\title{
UNIVERSIDAD Y GOBERNANZA: LA POLÍTICA DE LOS SABERES
}

Luis Fernando Bravo León 1

Estos son algunos apuntes sobre la universidad y la gobernanza. Para abordar estas reflexiones la hemos amparado en el concepto de política de los saberes. Entendemos como política de los saberes al papel central que cumple la universidad en la organización y gestión de las sociedades y los estados nacionales desde el origen mismo de la Universidad hasta el desafío planetario de la preservación de la vida. Por ello presentamos sus notas características, misionales y de la cultura académica, para el caso de la Universidad Santo Tomás, en la perspectiva de la definición de su naturaleza como universidad de estudios generales: Universidad de docencia que desarrolla investigación con orientación social.

\section{La Naturaleza de la Universidad}

- Universalidad: La pretensión fundacional de la universidad es las posibilidad de "volver sobre lo uno" es decir de abarcar la totalidad de los saberes de la época. En el siglo XIII los saberes unificadores son las artes, la teología, el derecho y la medicina. Son saberes con la autoridad del texto. Para el mundo moderno occidental serían las matemáticas de corte cartesiano. En la actualidad está en discusión este concepto por efecto de la crisis de la razón y de las catástrofes del siglo XX.

- Corporatividad: Es en el desarrollo de las ciudades medievales que las corporaciones se organizan como grupos de profesiones como oficio organizado para el servicio del "sacro imperio romano germánico". El oficio del intelecto se organiza en la universitas como conjunto de los hombres que se dedican al oficio del saber. De esta manera encontramos universidades de

\footnotetext{
${ }^{1}$ Docente investigador del DHFI y del grupo de Universidad y Gobernanza de la USTA.
} 
estudiantes (Bolonia) y universidades de maestros (París, Oxford). Es la comunidad la que hace la institución.

- Autonomía: Se reconoce como la jurisdicción de la universidad y su capacidad para darse sus propias reglas que se concreta en la figura del rector. Además se entiende como el derecho a huelga o de traslado (de esta manera nació Cambridge de un traslado, huelga de Oxford). Y el sentido más importante se entiende la autonomía como una forma particular de relación con el saber, cuyo privilegio está en la autoridad que da la enseñanza y la investigación.

- Criticidad: A diferencia de otras culturas en donde las castas sacerdotales y de adivinos tienen el privilegio del consejo y de la predicción; en el occidente medieval se concreta una institución, que por su carácter, es referente de saber comunitario. Así la universidad es criterio con respecto al pasado y su legado es tradición, y, a su vez, es criterio con respecto al futuro y su afán de innovación.

\subsection{Notas misionales}

- En la dimensión antropológica o de educabilidad, la labor fundamental de la universidad es ser Alma Mater, es decir formar en una "segunda naturaleza" a la persona. La formación se entiende como ese proceso de elevación de la vida particular y singular a un horizonte trascendente que permite la potenciación y el perfeccionamiento constantes en humanidad.

- En la dimensión epistémica o de relación con el saber, es decir enseñabilidad, la universidad se enfrenta a las maneras y modos en los que se configura el saber históricamente. Así, los textos son objeto de lectura (lectio), de pregunta (questio) y de debate (disputatio). Con el desarrollo de las disciplinas científicas (nacidas por fuera de la universidad) la relación se establece como 
investigación pura y aplicada. Hoy se debate entre las inter, las transdisciplinas y se enfrenta a un gran cambio de paradigma llamado desafío de complejidad.

- En la dimensión social o de pertinencia la universidad responde de manera local y global y se define como profesión de servicio en ordena la bien común y se encarna a la construcción de las naciones, de los estados (Universidad Napoleónica) y se inserta en la dinámica de globalización por su carácter internacional (desde sus orígenes). Así en esta dimensión los problemas y desafíos de los contextos se hacen intrínsecos al devenir histórico de la universidad.

\subsection{La cultura académica}

- La memoria: La tradición escrita es consustancial a la universidad, en ella se consigna la tradición, es decir, se trata de una institución de ocho siglos que no puede perder de vista sus orígenes y sus modos de ser histórica, por ello en líneas medulares (figuras modélicas) de USTA se concreta esta relación de memoria y de legado dominico que debe ser estudiado en conjunto con los estudiantes del convento, la facultad de Teología, de Filosofía y con el DHFI.

- La argumentación: el racionalismo como realismo crítico (pedagogía problémica) permite que los estudiantes y docentes discutan desde los desafíos de la realidad social. De este principio se practica un ejercicio constante de problematización del presente en el contexto de los municipios, las regiones, los países en un horizonte de desafío globales.

- La reorientación de la acción: a través de las líneas activas como anticipación y proyección la acción toma el rumbo de la transformación conforme a la comprensión de los contextos como un ejercicio de la comunidad académica de USTA - Colombia. Se trata entonces de orientar la acción conjunta de la universidad para hacerla acción 
política colectiva de los ciudadanos y de las organizaciones sociales para transformar la realidad conforme a la dignidad de los seres humanos y de las diferentes formas de vida (Laudato si).

\section{La universidad como política de los saberes}

En este capítulo pretende mostrar el papel de la cultura del texto y como esto se concretó en la formación de las universidades concomitantes con el proyecto político de Europa como Sacro Imperio Romano Germánico. Luego de los procesos de ruralización producido por los pueblos llamados bárbaros renace la necesidad de re-urbanizar y activar el comercio bajo el amparo de los Francos, y en especial, en el proyecto de unidad de fe y de lengua de Carlo Magno. Además, es en este contexto que la síntesis entre griegos, romanos y germanos se realiza al calor del cristianismo como fuerza aglutinante y de modo que la idea de un orbe cristiano se hace patente.

Con el edicto de Milán () el viejo imperio romano se cristianizó y el cristianismo se hizo imperio, lo que era marginal se hizo central. Este proceso evangelizador supuso también un proceso de inculturación, aculturación y emergencia de estructuras novedosas, buscar los orígenes de las formas de saber y de enunciar se encuentra en las dinámicas de la historia. Normalmente creemos que lo que pensamos y hacemos es original pero tiene una historia larga y abigarrada con múltiples síntesis y pérdidas, como todo en la vida, pero también en la novedad de lo que surge en este variopinto desarrollo de lo que sabemos.

El desarrollo de la ciencia en medio de este contexto se realiza como la preservación del saber de la antigüedad en los monasterios y en el desarrollo de la teología en los padres de la iglesia y en la aplicación de la lógica y de la metafísica griegas, además de lo realizado por los árabes en la recepción de Aristóteles que, por la España islámica, llega a Europa ya en el siglo XII. Esto para decir que las claridades y los oscurantismos son relativos a todas las épocas de la historia. Para Crombie (1996) la ciencia moderna encuentra solución de continuidad con esta época, a diferencia de Lindberg (2002) para quien la modernidad es un salto cualitativo sin continuidad con lo anterior. En fin los balances se harán al final de este recorrido. 


\subsection{El Imperio se cristianizó; el cristianismo se hizo imperial}

Una pequeña secta nacida en los confines de la Anatolia se fue propagando, y de ser una religión de catacumbas, pasó a ser la más importante para el imperio. Este lento proceso que se inicia con un pequeño grupo de pescadores, luego con un Saulo o Pablo de Tarso adquiere una dimensión universal y así, de a poco, va penetrando todos los niveles de la Roma antigua en su precipitado y gran proceso de apogeo y de destrucción.

Este nuevo mensaje (eu-vangelio, en griego buen mensaje) se va construyendo históricamente hasta convertirse en el humus de la Europa occidental y oriental, tanto de la Roma germana como de la Roma bizantina. De esta manera plantea Hans Küng su reflexión:

El concepto del cristianismo está determinado de continuo por su respectiva concreción histórica. La cristiandad puede convertirse en prisionera de la imagen que se ha hecho de sí misma en una determinada época. Cada tiempo tiene su propia imagen del cristianismo, nacida de una determinada situación, vivida y configurada por unas concretas fuerzas sociales y comunidades eclesiales, preformada o posformada en el plano conceptual por figuras y teologías concretas que dejan huella en el plano mental $(2006,23)$.

Así, en la forma en que se institucionaliza el cristianismo en el imperio romano va tomando las formas y los protocolos del mismo: la liturgia toma del teatro romano (también de lo ceremonial germánico), de la administración y organización romanas, del derecho en fin todo se entrecruza. No solo se da en Roma es también el caso de Bizancio en donde la pretensión se orienta más a la concepción de la divinidad de Jesús a diferencia de occidente en donde se resalta más la figura humana de Cristo. Es lo que Hans Küng llama el paradigma católico Romano Medieval. Lo llama así para dar cuenta de una variedad de estilos y de valores que forman un conjunto paradigmático para comprender de forma sintética los derroteros de la historia del cristianismo. 
No es sólo lo adquirido también es necesario dar cuenta de los aportes que como mensaje se va dando paulatinamente, hoy defendemos la idea de justicia sobre la idea de venganza, la idea de fraternidad sobre la de dominación, la idea de libertad interior o de consciencia frente a la alienación y opresión como lo enuncia Küng:

la historia y la esencia del cristianismo va unida a sus formas históricas y para el caso del saber occidental en su capacidad de penetración de todas las instancias de la vida social heredadas de Grecia y Roma: El cristianismo impregnaba ahora no sólo las instituciones políticas y las convicciones religiosas, sino también el pensamiento filosófico y la cultura artística. Una inculturación de una profundidad y amplitud que el cristianismo apenas alcanzó otra vez en paradigmas posteriores. El paganismo desaparecía progresivamente de la vida pública de las ciudades y pudo mantenerse sólo en ciertos habitantes de las ciudades de gran formación filosófica y en ambientes rurales, en los «aldeanos» (pagani). (2006, 198).

La historia de la evangelización de los pueblos llamados barbaros y la imbricación de formas míticas de los diferentes pueblos se mezclan y se interpenetran, es el caso del caldero como figura cultual de los antiguos Celtas que al cristianizarse se torna el santo grial, o la manera como se confunden las historias del rey Arturo y la idea del Mesías. Actualmente el caso más paradigmático es la obra de Tolkien "El señor de los anillos" el fondo es cristiano y la superficie son los mitos vikingos, germánicos y celtas, o también Narnia que conserva un fondo anglicano con las formas de antiguas tradiciones. Por demás está decir que la navidad es la mezcla de todas estas tradiciones con la idea de la encarnación de Dios que se celebra sobre el sócalo de tradiciones mediterráneas, germánicas, celtas y vikingas. 


\subsection{Los bárbaros y la destrucción de Roma Occidental: de la URBS a la RUS}

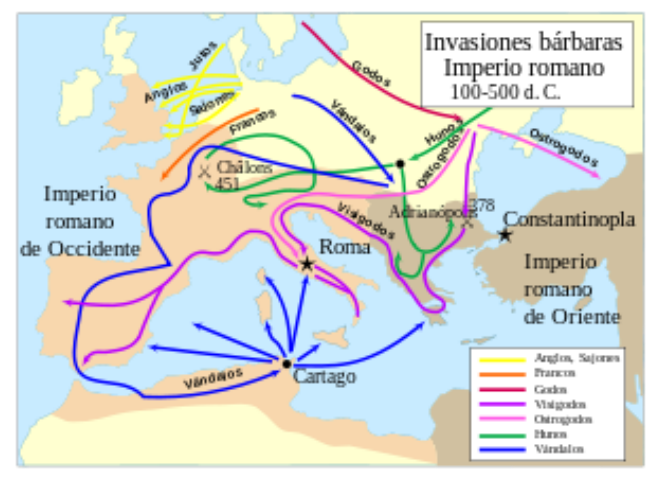

https://upload.wikimedia.org/wikipedia/commons/thumb/5/5d/Invasiones_b\%C3\%A1rbara s_Imperio_romano-es.svg/300px-Invasiones_b\%C3\%A1rbaras_Imperio_romano-

es.svg.png

Los pueblos de los confines que fueron sometidos poco a poco penetran el imperio y desde el 450 d.c y un poco antes los Hunos de ascendencia mongola y luego Alamanes, Godos, Francos y otros pueblos asolan a la debilitada Roma occidental. El legado y las formas urbanas se pierden en la fragmentación de las diversas migraciones, los caminos, los acueductos fueron destruidos. La civilización se pierde con la caída de las ciudades y su síntoma más evidente es la destrucción del acueducto. De la urbs con sus caminos, comercio e intercambio pasamos a la rus, la ruralización de Roma y la organización de pueblos germanos con la concepción no de ciudad sino de la tierra como eje fundamental para la preservación de la familia y de la nobleza de espada como forma de organización social.

Son las invasiones bárbaras las que colapsan al imperio, los Visigodos conquistan Hispania, los Francos a la Galia, posteriormente los Sajones, y Anglos a Britania, el norte de África por los Vándalos, en fin se destruye un orden y se transita a otros no muy claros. El saber romano con sus leyes y su organización quedan en Bizancio con su herencia Griega y en occidente son los monasterios en donde encuentra refugio. Son los monjes copistas, es decir, escritores y lectores, quienes preservan éste acervo. Es de destacar los monasterios Irlandeses de allí se va a llevar a cabo la evangelización de éstos pueblos. Y va ser un monje Alcuino de origen Anglosajón el encargado de revitalizar la cultura a través de las schollas monacales, patalinas y catedralicias. 
En el siglo V la conversión de Clodoveo rey Merovingio de los Francos, es el símbolo de la cristianización de estos pueblos, así como San Patricio en Irlanda o San Jorge en Inglaterra y san Andrés en Escocia las mentalidades se mezcla y se impregnan una a otras, el mestizaje se hace evidente en la liturgia, en las formas jurídicas, como lo describe Michel Foucault en 1976 en La verdad y las formas jurídicas, en la organización social y en los imaginarios colectivos: la contraposición naturaleza civilización, figuras del bosque y mitos mediterráneos.

Los Merovingios detienen el avance de los árabes y se convierten en los terratenientes en los inicios de la época medieval, pero es con los Carolingios antiguos senescales de las tierras merovingias que la historia toma el camino de la emergencia de Europa como unidad y proyecto político. Carlos Martel es el héroe iniciador pero quien consolida y legitima a estos mayordomos es Pipino el breve (apodado así por ser bajo de estatura) al hacerse coronar por el Papa, es el inicio de los estados pontificios y de la idea de un poder terrenal y divino de la Roma Sacra. Y quien concluye y da esplendor a este proyecto es Carlo Magno hijo de Pipino, no por casualidad el edificio emblemático de la unión europea lleva su nombre.

\subsection{Las culturas del texto: las schollas y la unidad de Europa}

La relación con los textos se remonta a la utilización de los rollos y de su lectura antigua hasta la forma códice que es la que conocemos hoy. La historia de la lectura será un tema clave para entender la circulación del saber y de las editoriales universitarias. Los rollos servían a la función pública y a la función sagrada su lectura estaba reservada a unos iniciados y a la casta sacerdotal para efectos de la administración. Tanto en Grecia como en Roma la lectura en voz alta cumplía la función de informar. La lectura personal de a poco se hace extensiva. 


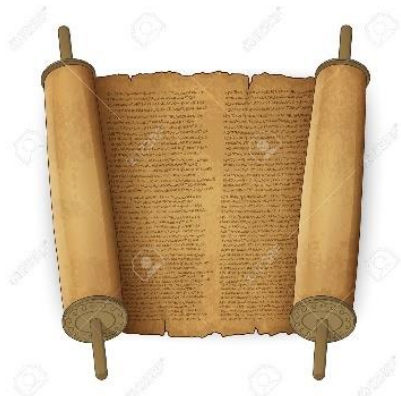

Rollo, volumen, antiguo

https://www.google.com.co/url?sa=i\&rct=j\&q=\&esrc=s\&source=images\&cd=\&cad=rja\&u $\underline{\text { act }=8 \& v e d=0 a h U K E w i R g 4 \_w 2 q T K A h W B X S Y K H V C A D V k Q j R w I B w \& u r l=h t t p \% 3 A \% 2 ~}$ F\%2Fes.123rf.com\%2Fclipart-

vectorizado\%2Ftora.html\&psig=AFQjCNFWPlGwYqmvj0chg6lnurEmjuU5ug\&ust=1452 $\underline{703084355633}$

El códice nace de un evento fortuito la escases de papiro, la leyenda lo ubica en el siglo III a. c en Pérgamo. Esta forma a partir de la piel de cordero o de asno permitió una mejor conservación y disposición para la lectura. En la edad media recibe un impulso importante al introducirle los índices y la paginación. Además de ser el elemento esencia de enseñanza (lectio). Ya en el momento der la imprenta la circulación de códices hizo popular la lectura personal y la formación de un criterio lejos de la autoridad eclesial. Es decir, es una $\underline{\text { antecedente de la formación de la subjetividad. }}$

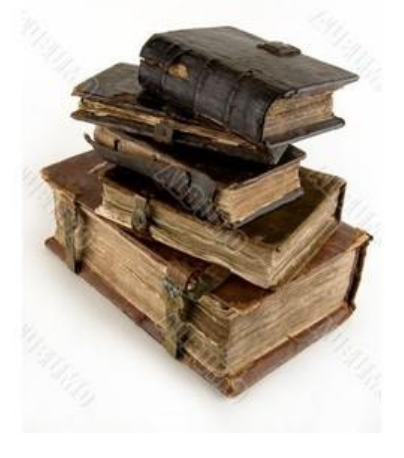

\section{Libros antiguos}

http://2.bp.blogspot.com/_lhFJL3fCVgM/S-

LvU7AyxuI/AAAAAAAAAFU/AIXnxyUZywk/s1600/libros+antiguos3.jpg 
En el 630 d.c el Islam emerge como una religión de la ortopráxis, a diferencia de la cristiandad medieval como ortodoxia, las dos son herederas del texto como referente de vida. En el islam el Corán es el texto por excelencia y en el cristianismo la Biblia, como la tradición de la Torá para la religión judía. Sobre la exégesis del texto se construye la interpretación y posterior aplicación de sus normas en todos los órdenes de la vida. Así, las consecuencias jurídicas, políticas y administrativas de los textos los hacen canónicos. Para el occidente cristiano ésta canonicidad se ve reflejada en los numerosos comentarios a los textos bíblicos y en la entronización de la auctoritas y de los autores. Por el lado del derecho, en el siglo VI las reformas de Justiniano recuperan y compilan en algo el poder de Roma desde Bizancio con el establecimiento del Corpus Iuris Justiniano. Además de la teología de San Agustín como modelo de razonamiento lógico y de argumentación de los asuntos de la fe y los asuntos de la razón.

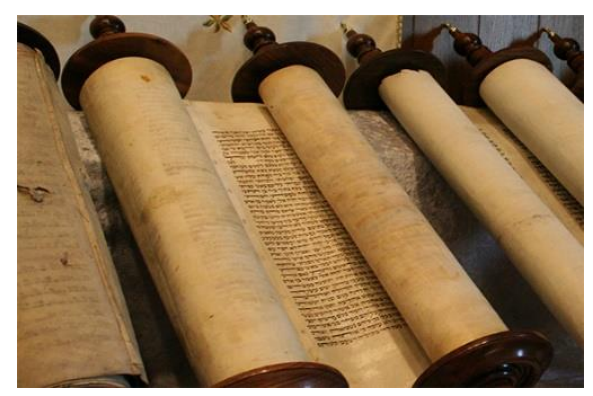

Rollos del antiguo testamento

\section{https://apologia21.files.wordpress.com/2015/03/rollos-del-antiguo-testamento.jpg}

Con Alcuino en la época de Carlo Magno (742 - 814) las reformas carolingias permiten un proyecto cultural de unidad de Europa (unidad de lengua, unidad de fe) sobre la base de la consolidación de las escuelas monacales (ya conocidas desde siglo VI), escuelas platinas y escuelas catedralicias. El currículo será las artes liberales quadrivium y trívium, dotando al Sacro Imperio Romano Germánico de los funcionarios y los clérigos necesarios para los oficios administrativos y de gobierno mismo. Proceso que ya en el siglo XI consolida la 
prosperidad europea gracias a cambios introducidos en la forma de sembrar y de organizar el comercio (molino de viento, rotación de tierras, etc).

Es un periodo de paulatina penetración de la cultura Árabe y por consiguiente de Aristóteles. Las escuelas de traducción de España, sobre todo Toledo, permiten conocer los comentarios de Averroes, Avicena, entre otros. Además de los avances de la medicina y el álgebra. En fin se trata de un intercambio en medio de las heridas causadas por las cruzadas y por el antagonismo religioso y por los mutuos intereses comerciales y políticos.

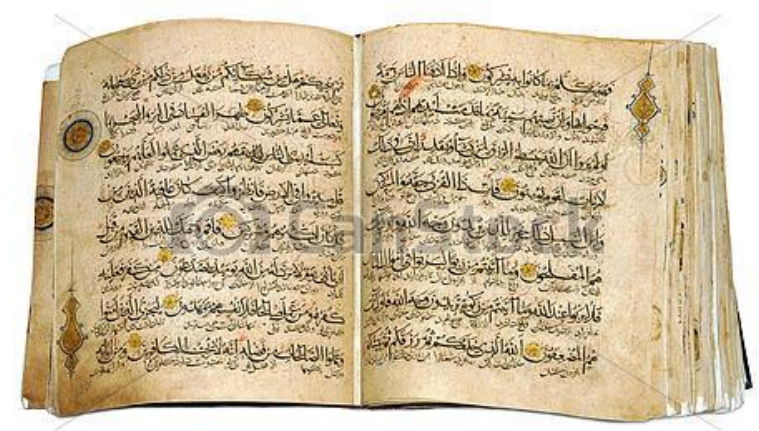

(C) Can Stock Photo - csp6109006

El Corán

http://comps.canstockphoto.es/can-stock-photo_csp6109006.jpg

\subsection{La UNIVERSITAS: Schollarum y Magistrorum}

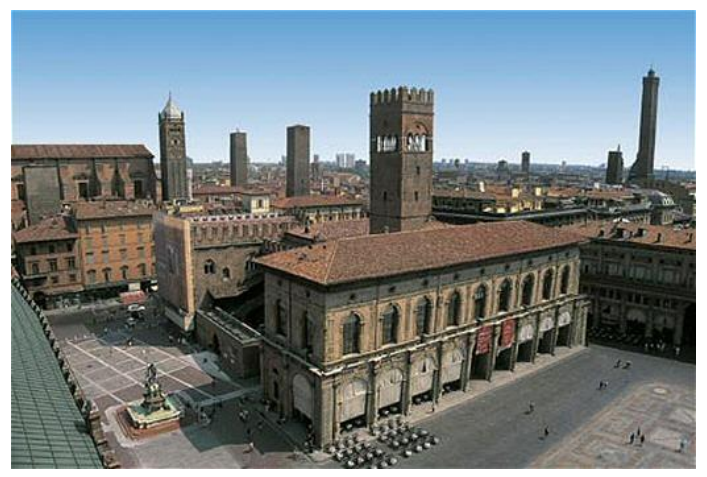

Universidad de Bolonia

http://www.incoming-students.com/wp-content/uploads/2013/02/Universidad-deBolonia.jpg 
En este contexto cuando aparece la universidad como institución clave para occidente. Con el renacer de la urbs medievales y las corporaciones que reúnen los diferentes oficios. Quienes se dedican al oficio del saber se organizan en una corporación de universitas magistrorum et schollarum.

El saber acumulado y las circunstancias de una Europa con necesidad de unidad para su preservación, precipitan que se desarrolle este proyecto. Las escuelas que corren con buena fama y las ciudades con sus catedrales símbolo del poder de la cristiandad, permiten el caldo de cultivo de un proyecto esencialmente urbano y con una dimensión de libertad para la investigación y el debate que no alcanzamos a dar cuenta en toda su dimensión en el presente ensayo.

Los continuos ataques de los mongoles y de los árabes ponen en peligro el territorio mismo, la unidad se logra frente al peligro. Éste afán de unidad para enfrentar al enemigo en muchos frentes hace que la Europa medieval actualice el propósito de imperio romano, y, conforme a su espíritu, realice la síntesis entre lo romano, lo cristiano y lo germánico. En este contexto la pretensión de totalidad del conocer con la sistematización teológica, jurídica y de la medicina completan el proceso iniciando con los estudios de las escuelas aplicadas a servir como formación básica en artes, es decir, pensar y hablar de allí la consideración que hace Le Goff de las artes liberales en la formación de los intelectuales de la edad media:

entre todas las ciencias (las artes liberales), se llaman artes, pues implican no sólo el conocimiento sino también una producción que deriva inmediatamente de la razón, como la función de la construcción (la gramática), de los silogismos (la dialéctica), del discurso (la retórica), de los números (la aritmética), de las medidas (la geometría), de las melodías (la música), de los cálculos del curso de los astros (la astronomía) (1996, 68).

Trivium y Quadrivium, reúnen el saber de artes pero es en la consideración y centralidad del saber acumulado, que hasta le fecha se reúne en textos antiguos, y de allí que se trate de reunir lo que más se pueda de manera sistemática en palabras de Juan de Salisbury citado por Le Goff: 
...cuantas más disciplinas se conozcan y cuanto más profundamente se impregne uno de ellas, más plenamente se captará la perfección de los autores (antiguos) y más claramente se los enseñará. Estos, gracias a la diacrisis, palabra que podemos traducir por ilustración o coloración, y partiendo de la materia bruta de una historia, de un tema, de una fábula, con la ayuda de todas esas disciplinas y de un gran arte de la síntesis y de la razón, hacían de la obra terminada como una imagen de todas las artes. La gramática y la poesía se mezclan íntimamente y abarcan toda la extensión del tema. Sobre ese campo, la lógica, al aportar los colores de la demostración, infunde sus pruebas racionales con el esplendor del oro; la retórica en virtud de la persuasión y del brío de la elocuencia imita el brillo de la plata. La matemática arrastrada por las ruedas de la cuadriga, pasa sobre las huellas de las otras artes y deja en ellas con una infinita variedad sus colores y sus encantos. La física, habiendo penetrado los secretos de la naturaleza, aporta la contribución del múltiple encanto de sus matices. Por fin, la más eminente de todas las ramas de la filosofía, la ética, sin la cual no hay filósofos ni siquiera de nombre, sobrepasa a todas las demás por la dignidad que confiere a la obra. Estudia atentamente a Virgilio o a Lucano y cualquiera que sea la filosofía que profeses, comprobarás que puedes acomodarla a ellos. En esto, según la capacidad del maestro y la habilidad y celo del alumno, consiste el provecho de la lectura previa de los autores antiguos. Este era el método que seguía Bernardo de Chartres, la más abundante fuente de las bellas letras en la Galia de los tiempos modernos (1996 29 $30)$.

En el horizonte fundacional encontramos entonces una triada que deja entrever la esencia de la universitas, como institución emblemática de occidente. A su vez cómo síntesis de los saberes y del ideal de conocer todo de todo (Philosuphus Doctus Ph.D) finalidad de la formación y símbolo del sabio occidental, cuyo maestro y figura será Santo Tomás de Aquino: Doctor Angellicus. Es decir, es en la universidad en donde se concreta el ideal de formación (alma mater) y de perfectibilidad del ser humano hasta alcanzar la universalidad de la imagen y semejanza de Dios. Los saberes están contenidos en el texto, conocer será saber leer de manera analógica lo que la canonicidad del texto dicta y su reflejo en el mundo. 
In Vestigium Ire, será el fin de la adecuación del mundo a lo que el texto dice. Así los textos claves serán: la Biblia como referente central, los comentarios y sentencias de los padres de la iglesia y de los doctores para el ámbito de la teología; para el caso del derecho será el códice de Justiniano el compendio del derecho romano; en la medicina los volúmenes (rollos) de Galeno el médico del siglo II d.c que inaugura y corrige la anatomía antigua. Saber es leer comentar y preguntar (Lectio, Questio, Disputatio).

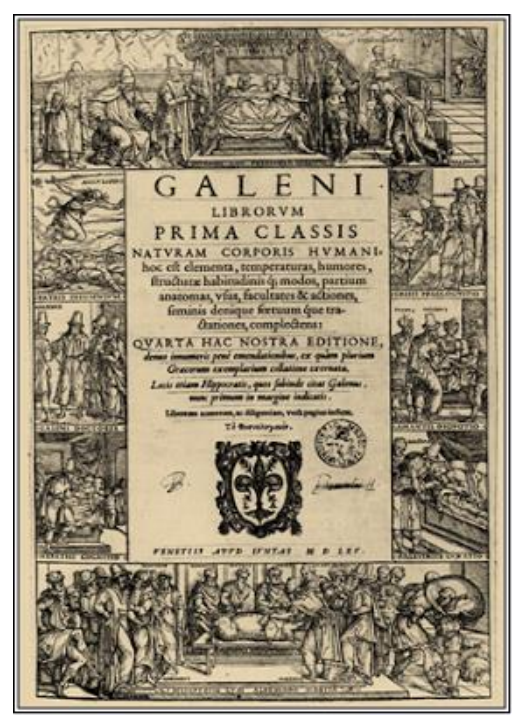

Portada de los volúmenes de Medicina de Galeno

http://2.bp.blogspot.com/-

bICjcnUVXJs/UUDKgxFSUCI/AAAAAAAAFok/FSJVGN_w7UA/s1600/28-historia-demedicina-galeno-de-pergamo.png

El saber de la medicina se concentra en la autoridad y los volúmenes de Galeno, un antiguo médico de gladiadores que ante la prohibición de abrir cuerpos logra corregir la medicina griega e introducir la anatomía. Los galenos serán los médicos que leen y discuten a Hipócrates, a Discorides y la tradición árabe de Avicena. 


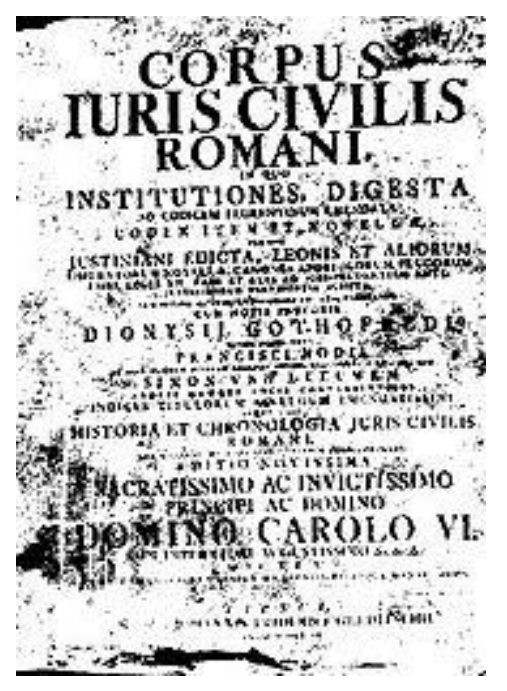

Portada del Corpus iuris civilis Romani

https://commons.wikimedia.org/wiki/File:Corpus_Iuris_Civilis_02.jpg

La lectura del derecho desde los decretos de Graciano al código de Justiniano se hace en forma de glosas, comentarios al pie de los textos y de su interpretación. Proceso conocido como jurisprudencia, la exegesis será el método de investigación que hasta hoy se practica en las instancias jurídicas. Saber será conocer las normas del derecho y de su distinción con el derecho canónico propio de la Iglesia.

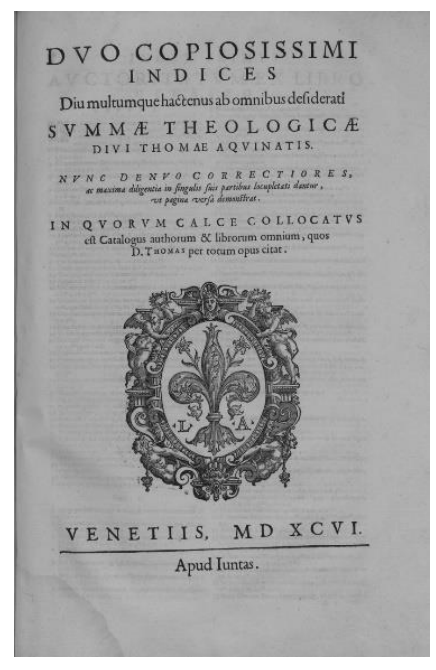

Portada de la Suma Teológica de Santo Tomás (en 1596) 
https://upload.wikimedia.org/wikipedia/commons/thumb/e/ec/Tommaso_-

_Summa theologica\%2C_1596_ 4593718.tif/lossy-page1-800px-Tommaso_-

_Summa_theologica\%2C_1596_-_4593718.tif.jpg

Así mismo, las summas son una compilación de lo más importante que un estudiante debía saber según la autoridad eclesial, estos ejercicios se realizaban para agudizar la memoria y sobre todo para establecer lo que se debe saber y conocer sobre la Sacra Scriptura además de las sentencias de Pedro Lombardo como autorictas. Los textos serán el instrumento de la labor intelectual propia de la corporación de la Universitas.

En el ámbito social la universitas está al servicio (profesión) del imperio en una correspondencia feudal de su organización: teología al servicio de la salvación del alma, derecho para la salvación del imperio y medicina al servicio de la salud del cuerpo (Le Goff, 1996, 71 - 91).

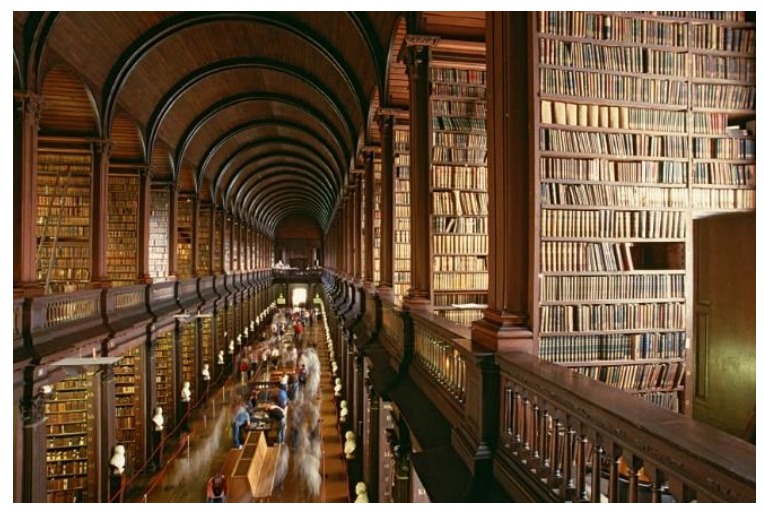

Biblioteca del Trinity College Dublin

\section{http://cdn.dublin.es/guias/dublin/fotos/trinity-college-old-library.jpg}

En principio las universidades nacen como centros internacionales cuyas características desarrolla muy bien el padre Borrero (2008, 29 - 34), en síntesis podemos decir que la autonomía, la sistematicidad, la universalidad y la criticidad son las notas más importantes. La autonomía se desarrolló como jurisdicción propia en el territorio, de aquí la labor del rector como figura de gobierno, además se entendió como autonomía en el oficio de pensar y de enseñar lo dilucidado, además de un rasgo interesante el derecho a huelga o traslado (así 
nació Cambridge de una huelga de Oxford). La sistematicidad implica empezar por las artes para luego acceder a las facultas como saber superior (teología, derecho y medicina) y de manera disciplinada alcanzar le título de doctus: el que lo sabe todo de todo (artes liberales y facultas). La universalidad como el abarcar los saberes de la época, ello es haber leído las auctoritas, los autores. La citica como referente para pensar el pasado (tradición) y para comprender el futuro (proyección).

Las universidades como instituciones hijas de occidente o mejor en su forma instituida, porque todos los pueblos tienen una idea de educación superior. En el caso de Europa las universidades se propagaron por toda la cristiandad y formaron el cuerpo de administradores del Sacro Imperio Romano Germánico. Así, cada nación fundó una escuela universitaria en sus procesos de consolidación y de creación de los nacientes estados. La proliferación de universidades hasta los confines del nuevo mundo da cuenta de su dinamismo. Ya en 1538 se inicia el proceso de fundación en la América española con el esquema de la Universidad de Salamanca y de los Estudios Generales propios de la Edad Media.

A la par de la estructura escolástica Europa fue desarrollando la modernidad y forjando los elementos que para el siglo XIX hacen que la universidad se transforme, estos son: la ciencia, el individuo-ciudadano y las sociedades como revolución-cambio. La investigación científica pura y aplicada, la consciencia de la libertad y la autonomía del individuo y la consideración de otras formas de organización política burguesa se consolidan en las reformas napoleónicas o universidad imperial y de la universalidad de Berlín cuyo centro será la investigación. Estas transformaciones se logran en el siglo XIX la ciencia moderna, el concepto de individuo y de sociedad como revolución serán los ejes, así en América Latina Francia es el referente y en el caso de los países anglosajones será Berlín su modelo.

Ya en el siglo $\mathrm{XX}$ con todos los horrores de la primera y segunda guerra mundial la universidad se democratiza y deja de ser una institución de élite. La cobertura y la masificación son los símbolos de estos cambios y de un cambio de época. La tragedia de las guerras cuestiona el talante ético y político de la ciencia; el quiebre del proyecto de occidente lleva a los ciudadanos a buscar alternativas a la civilización occidental. En todos estos cambios la universidad juega un papel protagónico y decisivo. La llegada de la mujer, la cobertura y la movilización social por el acceso y promoción universitaria permite la 
generación de nuevas ideas de sociedad que en la contracultura se concreta en la consigna de la imaginación al poder.

Hoy la universidad se enfrenta a un cambio de época. Los desafíos actuales como la crisis de la razón, la contracultura y el desafío de complejidad hacen de la institución universitaria un factor determinante en los variados cambios sociales de occidente y del mundo.

\section{Conclusión}

Luego de estos puntos a tener en cuenta podemos enfrentar al propósito de este escrito ¿cómo entender la relación entre4 Universidad y gobernanza como política de los saberes y en particular cuál es la naturaleza de Estudios Generales de la universidad Santo Tomás y específicamente como universidad de docencia que hace investigación con orientación social?

Lo primero que no hay que olvidar o mejor estudiar es la historia de la universidad y reconocer sus notas características. Es decir, entender la naturaleza para luego comprender su cualidad y propender por su calidad. No se trata de cualquier empresa, es una institución para la formación en lo superior y para lo superior con un horizonte de trascendencia en aras de una mayor humanización del género humano.

La USTA se comprende como una institución centrada en la formación de la persona, es decir, su centro está en una antropología que deriva su ideal del mensaje de Jesús y recoge la reflexión que durante muchos años ha permanecido en el horizonte del espíritu de la filosofía Tomista y su particular síntesis de la filosofía de Aristóteles. Por ello su fin está ordenado a este legado que se actualiza y entra en la corriente de los pensamientos contemporáneos, no en un afán dogmático y apologético, sino de sincero diálogo dialéctico.

En estas perspectivas se comprende que la idea original medieval de los estudios generales, en términos de la relación entre teología, filosofía y ciencias se hace hoy propuestas inter y transdisciplinares superando la artificial separación entre científicos y humanistas. Hoy las ciencias duras se hacen blandas y las ciencias blandas pretenden ser duras. Dicotomías que no dan cuenta de la actual condición del saber y sus articulaciones más que de la acumulación. Es decir, hoy los diálogos están al orden del día de la epistemología contemporánea. 
En otro sentido, los estudios generales se entienden como la posibilidad de compartir la formación de los clérigos y de los laicos, esto en los orígenes coloniales del claustro tomístico. Hoy diríamos que se trata de cooperar y compartir con los hombres de buena voluntad para generar mejores comprensiones sobre la complejidad de las realidades y abrirnos a un sentido no fundamentalista de la universalidad, sino reconociendo con humildad los límites de lo que podemos hacer, establecer redes de cooperación en aras de una inteligencia colectiva que permita afrontar los desafíos actuales de la realidad social.

En un último sentido los estudios generales permiten una comprensión que supera la miopía especializada y genera respuestas éticas y políticas en orden a la justicia distributiva de los bienes tangibles e intangibles. Esto es, formar en la prudencia requiere de sabiduría práctica para realizar las acciones pertinentes que los contextos sociales reclaman para conservar la fragilidad de las diferentes formas de vida y para comprendernos como parte de este pequeño y diverso universo. 
